\title{
Frequency and Severity of Premenstrual Syndrome among Undergraduate Medical Students
}

\section{Saira Yunus, ${ }^{1}$ Bushra Bano, ${ }^{2}$ Ayesha Farooq, ${ }^{3}$ Amtullah Zarreen ${ }^{4}$}

\begin{abstract}
Objective: To find out the frequency and to assess the degree of severity of premenstrual syndrome among undergraduate medical students

Methods:Methods: It is a Cross-Sectional Study conducted in 161 female Students of Allama Iqbal Medical College of 1 st year to final year who voluntarily consented for participation. PMS and its severity was diagnosed on the basis of a modified DRSP scale: mild if the score is 50-85, moderate if the score is 86- 120 and severe if the score is $>120$. Females having irregular periods or any organic pathology and those using hormonal contraception or any medication were excluded.Data was analyzed by SPSS version 23. Frequency, percentage charting was expressed for variables like presence of PMS and severity of PMS. Quantitative variables like age and BMI were expressed by Mean \pm S.D. Data was stratified for age, BMI, year of study, living status and marital status to deal with effect modifiers. Test of significance was applied i.e chisquare. A p-value $\leq 0.05$ was considered significant.

Results: Subjects ranged between 18-25 years with mean age of $19.9 \pm 2.1$ years. Majority of the students were between $18-20$ years. Mean BMI was $19.9 \pm 1.9 \mathrm{~kg} / \mathrm{m} 2$. Mean year of study was $2.4 \pm 1.3$ year. Out of 161 subjects, $53(32.9 \%)$ were living with parents while remaining $108(67.1 \%)$ were far from parents. Married students were $10(6.2 \%)$. Premenstrual syndrome was found to be in 31 females $(19.2 \%)$, mild $4.3 \%$, moderate $8.1 \%$ and severe $6.8 \%$, and severity was more in $4-5$ years students, p-value was found significant with variable years of study ( $p$-value $=0.095)$.

Conclusion: PMS was found in $19.2 \%$ of undergraduate medical students. Early recognition and timely management can improve the quality of performance among undergraduates.

Key Words: DRSP scale, Premenstrual syndrome, Undergraduates

How to Cite: Yunus S, Bano B, Farooq A, Zarreen A. Frequency and severity of Premenstrual Syndrome among undergraduate medical students. Esculapio.2020;16(04):29-32.

DOI: https://doi.org/10.51273/esc20.251646
\end{abstract}

\section{Introduction}

$\mathrm{D}$ efinition of PMS varies over the years because of its unknown etiology and its related symptoms complex. Globally Physicians are having different opinions about this malady. ${ }^{1}$ Reproductive age women often experience repeated psychological, physical and behavioral complexities occurring in second half of cycle and vanish by the end of menstruation. ${ }^{2}$ These symptoms really interfere with

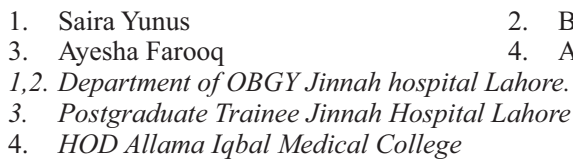

Correspondence:

Dr Saira Yunus, Assistant Professor,Email: sairaymian@gmail.com

$\begin{array}{ll}\text { Submission Date: } & 20-09-2020 \\ \text { 1st Revision Date: } & 30-09-2020 \\ \text { 2nd Revision Date: } & 04-11-2020 \\ \text { Acceptance Date: } & 16-12-2020\end{array}$

household, social, and workplace activities, inter personal and even the sexual functioning of a woman, which are not related to any organic or functional ailment. ${ }^{3}$ Some degrees of premenstrual problems are experienced by even younger girls in initial years following menarche. Many Studies depicts that around $80 \%$ of women may experience some of premenstrual symptoms in their reproductive age. ${ }^{4}$ When it is very severe, premenstrual syndrome is called as premenstrual dysphoric disorder (PMDD). The psychological symptoms are anger, frustration, emotional liability, depression and apprehension. Physical symptoms include weight gain, swelling, breast pain, headache, dizziness, and tingling sensations, so that psychiatric and endocrinal disorders must be checked before labelling a women PMS. Symptomatology which is triggered by ovulation, appears about one week before the start of periods and 
vanishes immediately after the start of periods. ${ }^{5}$ Due to the severity of symptoms and its prolonged history it is associated with long term effects on the emotional health, relationships and impairment in work. Women suffering PMS report significant family disharmony, inability to perform at workplace along with frequent absence from work, school, or college. Very few Data is available on PMDD in young girls. ${ }^{6}$ In a study, it was concluded that, the prevalence of premenstrual syndrome was $39.6 \%$. The distribution of severity of symptoms was minimal $2.5 \%$, mild $27.5 \%$, moderate $42.5 \%$, severe $25 \%$ and extreme $2.5 \%{ }^{7} 1 \mathrm{n}$ another study, prevalence of PMS was found around $18.4 \%$ and moderate to severe PMS was found in $14.7 \%{ }^{8}$

\section{Results}

Subjects ranged between 18-25 years with mean age of 19.9 \pm 2.1 years. Majority of the students were between 18-20 years. Mean BMI was $19.9 \pm 1.9 \mathrm{~kg} / \mathrm{m}^{2}$.

Table 1: Demographic Profile of Subjects

\begin{tabular}{lccc}
\hline & $\begin{array}{c}\text { Variables } \\
\mathbf{n = 1 6 1}\end{array}$ & Frequency & $\begin{array}{c}\text { Percentage } \\
\text { \% }\end{array}$ \\
\hline Age Mean & $18-20$ & 109 & 67.7 \\
$=19.9 \pm 2.1$ & $21-25$ & 52 & 32.3 \\
BMI Mean & $\leq 18$ & 26 & 16.1 \\
$=19.9 \pm 1.9$ & $\geq 18.1$ & 135 & 83.9 \\
& $1-3$ Years & 125 & 77.6 \\
Year of study & $4-5$ Years & 36 & 22.4 \\
& Parental House & 53 & 32.9 \\
Living Status & Independent/Boarding & 108 & 67.1 \\
& Single & 151 & 93.8 \\
Marital Status & Married & 10 & 6.2 \\
Pre Menstrual & Yes & 31 & 19.2 \\
Syndrome & No & 130 & 80.8 \\
& Normal & 130 & 80.8 \\
Severity of & Mild & 7 & 4.3 \\
Pre Menstrual & Moderate & 13 & 8.1 \\
Syndrome & Severe & 11 & 6.8 \\
& & &
\end{tabular}

Mean year of study was $2.4 \pm 1.3$ year. Out of 161 subjects, 53(32.9\%) were living with parents while remaining $108(67.1 \%)$ were far from parents. Married students were $(6.2 \%) \mathrm{n}=10$. (Table -1) Premenstrual syndrome was found in 31 females (19.2\%), mild $4.3 \%$, moderate $8.1 \%$ and severe $6.8 \%$ (Table-2). Stratification for age, BMI, year of study and marital status was also done (Table-2) and pvalue was found significant in 4-5 years of study ( $p$ value $=0.095$ ). out of total 125 students of $1-3$ years
Table 2: Pre Menstrual Syndrome \& Independent Variables Cross Tabulation

\begin{tabular}{|c|c|c|c|c|c|c|}
\hline \multirow{2}{*}{\multicolumn{2}{|c|}{ Variables }} & \multicolumn{3}{|c|}{ Pre Menstrual Syndrome } & \multirow{2}{*}{-Total } & \multirow{2}{*}{$\begin{array}{c}P \\
\text { Value }\end{array}$} \\
\hline & & \multirow{2}{*}{$\begin{array}{c}\text { Mild } \\
6\end{array}$} & \multirow{2}{*}{$\begin{array}{c}\text { Moderate } \\
8\end{array}$} & \multirow{2}{*}{$\begin{array}{c}\text { Severe } \\
6\end{array}$} & & \\
\hline Age & $18-20$ & & & & 20 & \multirow{2}{*}{0.386} \\
\hline & $21-25$ & 1 & 5 & 5 & 11 & \\
\hline & Total & 7 & 13 & 11 & 31 & - \\
\hline \multirow{3}{*}{$\begin{array}{c}\text { BMI } \\
\left(\mathrm{Kg} / \mathrm{m}^{2}\right)\end{array}$} & $\leq 18$ & 1 & 1 & 1 & 3 & \multirow{2}{*}{0.890} \\
\hline & $\geq 18.1$ & 6 & 12 & 10 & 28 & \\
\hline & Total & 7 & 13 & 11 & 31 & - \\
\hline \multirow{3}{*}{$\begin{array}{c}\text { Year Of } \\
\text { Study }\end{array}$} & $1-3$ & 7 & 10 & 6 & 23 & \multirow{3}{*}{$0.095^{*}$} \\
\hline & $4-5$ & 0 & 3 & 5 & 8 & \\
\hline & Total & 7 & 13 & 11 & 31 & \\
\hline \multirow{3}{*}{$\begin{array}{c}\text { Marital } \\
\text { Status }\end{array}$} & Single & 7 & 10 & 11 & 28 & \multirow{2}{*}{1.00} \\
\hline & Married & 0 & 3 & 0 & 3 & \\
\hline & Total & 7 & 13 & 11 & 31 & - \\
\hline
\end{tabular}

PMS was found I 23 students (18.4\%) and out of 36 students of 4-5 years it was found in 8 students $(22.2 \%)$. Out of those 8 students In $4-5$ years 5 had severe and 3 had moderate PMS. (Table-2)

\section{Discussion}

Many women in their reproductive age may experience physical or emotional symptoms before the start of periods. Amongst these, some are so badly affected that it impairs their mental and physical health, relationships, and quality education. ${ }^{9}$ It is also observed that premenstrual syndrome (PMS) exists more among single women, between 35-44 years, and in women of low income groups living in deprived areas. ${ }^{10,11}$ Multiple risk factors are revealed with PMS in several studies, including age, stress, marital status and body mass index. These risk factors were found to worsen the manifestations. ${ }^{12}$ A significant number of women in Pakistan experience PMS but they don't come up with this idea of suffering a disorder. ${ }^{13}$ In our country, menstruation and related feminine issues are taken as taboos and women are forced to accept that PMS is not a significant issue to be talked about or to seek advice for, even if it adversely affect their lives. ${ }^{13} \mathrm{PMS}$ is a symptom complex of physical and psychological symptoms appearing prior to the onset of periods and resolves with the onset of menstruation or within few days of menstruation. ${ }^{14}$ Our sample is comparable with past similar studies, and the mean age of all participants is $19.9 \pm 1.6$ years and the majority of them are urban resident and single. The participants from previous studies were also from similar age group college students, had urban residence, and were unmarried. ${ }^{15-18}$ In current study, 
the frequency of PMS is $19.2 \%$ (14.9\% for moderate to severe PMS and $4.3 \%$ for mild) among undergraduate medical students. It is in agreement with the study done by Rapkin and Mikacich ${ }^{19}$ and other studies from Asian countries among this population. ${ }^{20}$ This finding is also consistent with two other studies BY lentz \& parry. ${ }^{21,22}$ The prevalence of severe and mild PMS in this study is not in agreement with the study by Steiner et al who reported $21.3 \%$ and $8.3 \%$, respectively, and also differs from study by Chayachinda et $\mathrm{al}^{23}$ who reported 25.1\% PMS among Thai nurses. The lower prevalence in our study can be explained by influence of cultural norms, social factors, peer experiences, local practices and life stresses about menstruation in Pakistani context which affects both experiencing and reporting of the premenstrual symptoms.

In present study no statistically significant relationship was established amongst subjects in relation to age, BMI, marital status and living conditions, which is in consistent with study of Nour Bkhashani et al, ${ }^{16}$ except age which showed higher prevalence in younger 18-20 years, which may be because in present study sample size smaller for that study.

\section{Limitations and Challenges}

This study only reflects one medical institute and such more studies should be conducted in other educational systems to better understand the true picture of existing data for this disorder and to establish the triggering factors and available management options. Another limitation of present study is use of subject's selfreported data due to which there is possibility of higher expression of disorder amongst subjects.

\section{Conclusion}

In conclusion, PMS was found in $19.2 \%$ of undergraduate medical students of government medical college of Pakistan. Frequency and severity of PMS was more in 4th and final year students. Worldwide it is a common problem and awareness about the existence of this medical problem and early recognition along with timely management, among undergraduates the quality of their performance can be improved.

\section{Conflict of Interest: None}

\section{References}

1. Attar K. Epidemiology of Premenstrual Syndrome, a Systematic Review and Meta-Analysis Study. J Clin Diag Res 2014; 8:106-9.

2. Biggs WS, Demuth M. Premenstrual syndrome and premenstrual dysphoric disorder. Am Fam Phys 2011; 84:918.

3. Subhash B Thakre, Sushama S Thakre, Suresh Ughade, Amol D Thakre. Urban-rural differences in menstrual problems and practices of girl students in Nagpur, India. Indian Pediatrics 2012; 49:733-6.

4. Ramya S, Rupavani K, Bupathy A. Effect of educational program on premenstrual syndrome in adolescent school girls. Int J Reprod Contracept Obstet Gynecol 2014; 3:168-71.

5. Sarkar A, Mandal R, Ghorai S. Premenstrual syndrome among adolescent girl students in a rural school of West Bengal, India. Int J Med Sci Public Health. 2015; 1 .

6. Tacani P, de Oliveira Ribeiro D, Banos Guimaraes B, Perez Machado A, Tacani R. Characterization of symptoms and edema distribution in premenstrual syndrome. Int J Women's Health 2015; 7:297-303.

7. Badkur D, Wanjpe A, Singh S, Chouhan DS, Sinha A. Premenstrual syndrome among female students of colleges in Ujjain City, Madhya Pradesh. Int J Comm Med 2016; 7:878-81.

8. Raval CM, Panchal BN, Tiwari DS, Vala AU, Bhatt RB. Prevalence of premenstrual syndrome and premenstrual dysphoric disorder among college students of Bhavnagar, Gujarat. Ind J Psy 2016; 58:164.

9. Quintana-Zinn FA, Whitcomb BW, Ronnenberg AG. Premenstrual symptom patterns and behavioral risk factors in young women: a cross-sectional study. J Womens Health (Larchmt) 2017; 26:1099-1105.

10. Cheng SH, Sun ZG, Lee IH. Perception of premenstrual syndrome and attitude of evaluations of work performance among incoming university female students. Biomed J 2015; 38:167-72.

11. Shershah S, Morrison JJ, Jafarey S. Prevalence of premenstrual syndrome in Pakistani women. Pak MedAssoc 1991; 41:101-3.

12. Hamaideh SH, Al-Ashram SA, Al-Modallal H. Premenstrual syndrome and premenstrual dysphoric disorder among Jordanian women. J Psychiatr Ment Health Nurs 2014; 21:60-6.

13. Pal SA, Dennerstein L, Lehert P. Pakistan Medical Association; 2011. Premenstrual symptoms in Pakistani women and their effect on activities of daily life. J Pak Med Assoc 2011; 61:763-8.

14. Silva CM, Gigante DP, Carret ML, Fassa AG. Population study of premenstrual syndrome. Rev Saude 
Publica 2006; 40:47-56.

15. Steiner M, Peer M, Palova E, Freeman EW, Macdougall M, Soares CN. The premenstrual symptoms screening tool revised for adolescents (PSST-A): Prevalence of severe PMS and premenstrual dysphoric disorder in adolescents. Arch Women Ment Health 2011; 14:77-81.

16. Bakhshani NM, Mousavi MN, Khodabandeh G. Prevalence and severity of premenstrual symptoms among Iranian female university students. J Pak Med Assoc 2009; 59:205-8.

17. Issa BA, Yussuf AD, Olatinwo AW, Ighodalo $\mathrm{M}$. Premenstrual dysphoric disorder among medical students of a Nigerian university. Ann Afr Med 2010; 9:118-22.

18. Singh P, Kumar S, Kaur H, Swami M, Soni A, Shah R, et al. Cross sectional identification of premenstrual syndrome and premenstrual dysphoric disorder among college students: A preliminary study. Indian J Priv Psychiatry 2015; 9:21-7.

19. Rapkin AJ, Mikacich JA. Premenstrual syndrome and premenstrual dysphoric disorder in adolescents. Curr Opin Obstet Gynecol 2008; 20:455-63.

20. Nourjah P. Premenstrual syndrome among teacher training university students in Iran. J Obstet Gynecol India 2008; 58:49-52.

21. Lentz GM. Primary and secondary dysmenorrhea, premenstrual syndrome, and premenstrual dysphoric disorder-etiology, diagnosis, management. In: Lentz GM, Lobo RA, Gershenson DM, Katz VL, editors. Comprehensive Gynecology. Part V. 6th ed. Philadelphia: Elsevier, Mosby; 2012. pp. 791-802.

22. Parry BL, Berga SL. Premenstrual dysphoric disorder. In: Sadock BJ, Sadock VA, editors.Kaplan \& Sadock's Comprehensive Textbook of Psychiatry. 8th ed. Vol. II. Baltimore: Lippincott Williams \& Wilkins; 2005. p. 2316-23.

23. Chayachinda C, Rattanachaiyanont M, Phattharayuttawat S, Kooptiwoot S. Premenstrual syndrome in Thai nurses. J Psychosom Obstet Gynaecol. 2008; 29: 199-205.

\section{Authors Contribution}

YS: Data Compilation, Writing

BB: Data Analysis

FA: Data Collection

ZA: Expert Advice 